\title{
The impact of the COVID-19 pandemic on the dental-maxillofacial emergency service of a German university hospital in the year 2020
}

\author{
D. G. E. Thiem ${ }^{1} \cdot$ M. Polsak ${ }^{1} \cdot$ P. Römer ${ }^{1} \cdot$ M. Gielisch ${ }^{1} \cdot$ S. Blatt ${ }^{1}$ • B. Al-Nawas ${ }^{2} \cdot$ P. W. Kämmerer ${ }^{1}$
}

Received: 21 March 2021 / Accepted: 23 April 2021 / Published online: 26 June 2021

(c) The Author(s) 2021

\begin{abstract}
Objectives COVID-19 is considered one of the most serious pandemic in history and has posed major challenges to the world's health care. Dentistry and oral and maxillofacial surgery (CMFS) are particularly affected due to direct exposure to the respiratory tract, as the reservoir of SARS-CoV-2. In this study, the impact of the COVID-19-pandemic on a dental and CMFS emergency services in Germany in 2020 was first time investigated and correlated with governmental restriction measures in public life.

Materials and methods Epidemiological data of a German University Hospital were analysed from a total of 8386 patients in 2019 and 2020. Parameters included information on demographics, time, weekday and reason for presentation, as well as diagnosis and therapy performed. Data from 2020 were compared with those from 2019, taking into account the nationwide periods of public life restrictions.

Results In 2020, 22\% fewer patients presented via dental and CMFS emergency service. In a monthly comparison, there were negative peaks of up to $-41 \%$ in November, but also a plus of $26 \%$ in July. The largest decreases were recorded during the lockdown periods in spring $(-33 \%)$ and winter $(-39 \%)$. Further, a threefold increase in actual emergencies and inpatient admissions revealed during these time periods $(p<0.001)$.

Conclusions COVID-19 pandemic had a significant impact on the dental and CMFS emergency service in 2020 resulting in more severe cases.

Clinical relevance This study underlines the importance of maintaining an emergency service system and basic outpatient care in these specialities, which requires uniform recommendations from the medical-dental societies and politics.
\end{abstract}

Keywords Government guidelines $\cdot$ CMFS $\cdot$ Primary care $\cdot$ SARS-CoV-2 $\cdot$ Healthcare system

\section{Introduction}

In Germany, the provision of emergency dental services is regulated by the associations of panel dentists on the basis of a guarantee mandate. According to this, all dentists in private practice must participate in principle in the dental emergency service on the basis of the professional regulations of

P. W. Kämmerer this author share senior authorship

D. G. E. Thiem

daniel.thiem@uni-mainz.de

1 Department of Oral and Maxillofacial Surgery, Facial Plastic Surgery, University Medical Centre Mainz, Augustusplatz 2, 55131 Mainz, Germany

2 Department of Oral and Maxillofacial Surgery, School of Dentistry, Kyung Hee University, Seoul, Korea the respective applicable health professional chamber laws. In some cities with dental universities, the emergency dental service is provided by the dentists in private practice and the university hospitals. The definition of dental emergencies is inconsistent and not clearly defined. According to a German-language statement from 1994, a distinction is made between absolute (accidental injuries in the dental, oral and maxillofacial region, post-operative bleeding after dental surgery and odontogenic infections) and relative indications (all other diseases originating from the dental system with pain symptoms) for emergency therapy, which are also the most common reasons for emergency presentations in most industrialised countries [1-3]. The situation is different for emergencies in the field of oral and maxillofacial surgery, which require immediate therapy much more frequently. These include extended cervicofacial infections, fractures of the alveolar process and mandible, as well as of 
the central and centrolateral midface. In most cases, dental emergencies are not life-threatening but can be painful and/or cosmetically significant. Coronavirus disease 2019 (COVID-19), caused by the severe acute respiratory syndrome coronavirus 2 (SARS-CoV-2), has caused much public fear and confusion and has affected the delivery of vital health services, including dental care. In the context of the COVID-19 pandemic, the recommendations of the dental societies differed in a worldwide comparison. For example, in an interim guidance on the management of emergency and urgent dental care, on 16 March 2020, the American Dental Association (ADA) recommended treating dental emergencies only and published a triaging action recommendation $[4,5]$. The Scottish Dental Society referred to an existing recommendation on emergent, urgent and standard care triage $[6,7]$. In contrast, the Federal Dental Association in Germany advocated the maintenance of dental care and the implementation of preventive and therapeutic measures, taking into account appropriate hygiene standards. Timely and major reorganization of dental care services is challenging. Early management of acute dental emergencies is important to avert patients from Accident and Emergency services and to avoid hospital admissions. One concern is that with the suspension of routine dental care, more patients than usual could need admission for the management of acute dental infections that threaten the airway and require intensive care. This study is one of the first, along with a few others [8], to examine the impact of the wavelike COVID-19 pandemic on the emergency dental and oral and maxillofacial surgery services of a university hospital over time from January 2020 to 31 December 2020 in comparison with 2019.

\section{Materials and methods}

In this retrospective study, all patients presenting to the dental and oral and maxillofacial emergency services of the Johannes Gutenberg-University Hospital Mainz, Germany in the COVID-19 pandemic year 2020 (1 January 2020 to 31 December 2020) were analysed $(n=3679)$. The patient collective from 2019 served as the comparison group $(n=4707)$. The study was approved by the local ethic committee of Rhineland-Palate (registration number 2020-15,530) and was conducted in accordance with the protocol and in compliance with the moral, ethical and scientific principles governing clinical research as set out in the Declaration of Helsinki of 1975 as revised in 1983. Outside regular opening hours, the dental emergency service was available from 17:00 to 22:00 on Mondays to Fridays and from 08:00 to 22:00 on weekends and public holidays. Outside regular opening hours, the oral and maxillofacial emergency service was available Mondays to Thursdays from 17:00 to the following day at 07:30, and continuously from Fridays at 13:00 to Mondays at 07:30.

According to the emergency service times, a list of all patients presenting during this period was created using the search filter function of the hospital system (SAP SE, Germany). Subsequently, each medical record of the total of 8386 included patients was screened for the following parameters and the information was recorded in a previously created Excel table. In each case, 1677 patient cases were processed by one of the five authors involved. After complete recording, all data were coded for statistical processing according to the groups described in M\&M. Patient demographic characteristics such as gender, age, pregnancy, co-morbidities and specific long-term medications were recorded, as well as information on the reason (Table 1) and type (i.e. autonomous visit, referral, consultative, via rescue service) of presentation, diagnosis, diagnostic imaging (orthopantomography (OPT), cone beam computed tomography (CBCT), dental film, CT, sonography, MRI) and treatment. Co-morbidities of interest recorded were heart disease (e.g. previous myocardial infarction, arrhythmia, myocarditis, heart failure, coronary artery disease), hypertension,

Table 1 Characteristics of patient-reported reasons for presenting during emergency hours

\begin{tabular}{l} 
Patients' reason for presentation \\
\hline Pain \\
Accident \\
Orofacial swelling \\
Scheduled presentation for follow-up care \\
Dental conservative issues \\
- Loosened fillings (resin composite) \\
- Lost coronal seal (Cavit) \\
- Tooth structure defects \\
Tooth fractures \\
(Post) bleeding \\
Assault \\
Others \\
Orthodontic issues \\
- Loosened orthodontic devices \\
- Sharp-edged wire ends \\
Pus/fistula \\
Teething \\
Implant issues \\
- Loosened gingiva former or cover screw \\
- Loosened implant crown \\
Oral mucosal changes \\
Prosthetic issues \\
- Problems with prosthetic dentures and restorations \\
TMJ dislocation \\
Postoperative complications \\
\end{tabular}


diabetes (type I and type II), any form of autoimmune disease, epilepsy, lung disease (asthma, chronic obstructive pulmonary disease (COPD), pulmonary fibrosis), congenital or acquired coagulopathies, as well as thyroid, kidney or liver disease. From March 2020, corona risk assessment was carried out on every scheduled or emergency patient. From March 2020 onwards, the COVID risk classification of each scheduled or emergency patient was carried out by means of a special questionnaire on personal travel history to risk regions/countries, clinical symptoms or previous contacts with COVID-positive tested persons or suspected cases in the personal environment. With regard to long-term medication, we focused on therapy-influencing drug groups such as oral anticoagulants, antiplatelet agents, dual and triple regimes of anticoagulation, antidiabetics and antihypertensives. The subdivision into diagnosis types/groups was as follows: conservative dental issues (e.g. acute pulpitis, periodontitis, tooth structure defects, loosened fillings, caries), trauma (e.g. anterior dental trauma, intra- and extraoral trauma, fractures of the midface, mandible or alveolar process), infections (e.g. submucosal abscess, periodontal abscess, lodge abscess, pericoronitis, maxillary sinus empyema, cervicofacial inflammations (e.g. phlegmon, superficial phlegmon, superinfected atheroma, infected wounds)), other disease (diseases of the oral mucosa (e.g. gingivitis, leukoplakia, erythroplakia, unclear tissue proliferation, mouth burning), defective orthodontic appliance, bone cyst, oroantral communication, sialadenitis, temporomandibular joint diseases (TMJ) in general, TMJ luxation, postoperative complications (e.g. wound dehiscence, wound infections, dry socket, swelling, pain), animal bites, sinusitis, cervicofacial emphysema, lymphadenopathy, prosthetic problems (e.g. denture pressure point, denture fracture, implant-associated problems (e.g. loosened cover screw or gingiva former)), cancer, scheduled follow-up presentations, bleeding (e.g. postoperative bleeding) and pain (craniofacial pain/discomfort with no clear aetiology, trigeminal neuralgia).

Further, the diagnoses were grouped into emergent ${ }^{+++}$, urgent ${ }^{++}$and non-urgent ${ }^{+}$according to their need for treatment, following the classification scheme of the Scottish Dental Society. The different therapy measures were assigned to the following therapy groups for a better overview: splinting (i.e. using bony and dental-supported mandibulo-maxillary fixation, segmental wire-composite splints, titanium trauma splints, Schuchardt splints), dental conservation measures (i.e. resin composite filling, smoothing of sharp tooth or restoration edges), endodontic measures (i.e. trepanation, vital pulp extirpation, root canal treatments), surgical measures (i.e. extra-oral and/or intraoral wound closure, haemostasis by means of vascular transection, mucoplasty, extraction of teeth or tooth remnants not worth preserving, extraoral incision and drainage of lodge abscesses), intraoral abscess incision and drainage, local haemostyptic haemostasis via tranexamic acid swab or silicone squeeze bite, conservative (symptomatic noninvasive) measures (i.e. prescription of oral painkillers, local cold application or soft-liquid food), follow-up measures (bandage or drainage change, suture removal, irrigation of an abscess cavity or maxillary sinus), TMJ repositioning, prescription of antibiotics, hospital admission and other isolated measures. More than one therapeutic intervention was recorded per patient case, where applicable. The epidemiological data on the development of COVID-19 infection figures in Germany were taken from the COVID-19 Dashboard (https://experience.arcgis.com/experience/47822 0a4c454480e823b17327b2bf1d4), the platform officially used by the Robert Koch Institute to provide the population with daily updates. Key figures on the worldwide COVID-19 situation are taken from statistical data on COVID-19 from the search engine platform Google (Google LLC, California, USA), whose sources include the free internet encyclopaedia Wikipedia, ministries of health or newspaper publishers such as the New York Times.

\section{Statistics}

Raw data sets were saved in Excel sheets (Microsoft Corporation, Redmond, USA) and subsequently transferred into SPSS Statistics (version 26.0.0.0, MacOS X; SPSS Inc., IBM Corporation, Armonk, NY, USA). Data were expressed as mean $(\mathrm{M}), \mathrm{SD}_{ \pm}$, minimum (min), maximum (max) and SEM. Normal distribution was checked using non-parametric Kolmogorov-Smirnov test (KS test) and results were analysed for statistical significance by the use of ANOVA $={ }^{(\#)}$, unpaired non-parametric Mann-Whitney $U$ tests $={ }^{(\$)}$ and Students' $t$ test ${ }^{(*)} . P$ values of $\leq 0.05$ were termed significant. Line and bar charts were used for illustration purposes. Timeline graphics were created with Office Timeline Pro (Microsoft Corporation, Redmond, USA).

\section{Results}

\section{Dental emergency service-characteristics before and during COVID-19 pandemic}

In 2020, a total of 3679 patients (female $=1675$ and male $=2004$ ) presented from 1 January to 31 December. In 2019, a total of 4707 patients (female $=2121$ and male $=2586$ ) presented through the University Hospital's emergency dental service during the same period. The average patient age in 2020 was 37.6 ( $\min 0$, max 96) and 37.2 years ( $\min 0, \max 98$ ) in 2019. The number of emergency presentations in 2020 decreased by a total of 1026 patients $(22 \%)$ compared with 2019 . Broken down by 
Table 2 Trend in patient numbers in dental and craniomaxillofacial emergency services by month in comparison between 2019 und 2020

\begin{tabular}{llll}
\hline Month & Year 2019 $(\%)$ & Year 2020 (\%) & $\begin{array}{l}\text { Difference } \\
2019 \text { vs. } \\
2020\end{array}$ \\
\hline January & $386(8.2)$ & $290(7.9)$ & $-25 \%$ \\
February & $354(7.5)$ & $312(8.5)$ & $-12 \%$ \\
March & $397(8.4)$ & $272(7.4)$ & $-31 \%$ \\
April & $450(9.6)$ & $293(8)$ & $-35 \%$ \\
May & $359(7.6)$ & $354(9.6)$ & $-1 \%$ \\
June & $442(9.4)$ & $277(7.5)$ & $-37 \%$ \\
July & $317(6.7)$ & $399(10.8)$ & $+26 \%$ \\
August & $405(8.6)$ & $366(9.9)$ & $-10 \%$ \\
September & $394(8.4)$ & $291(7.9)$ & $-26 \%$ \\
October & $353(7.5)$ & $289(7.9)$ & $-18 \%$ \\
November & $355(7.5)$ & $209(5.7)$ & $-41 \%$ \\
December & $495(10.5)$ & $329(8.9)$ & $-33 \%$ \\
Total & $\mathbf{4 7 0 7}$ & $\mathbf{3 6 7 9}$ & $-\mathbf{2 2 \%}$ \\
\hline
\end{tabular}

calendar month, a similar picture emerges in percentage terms when comparing the calendar years 2019 and 2020 (Table 2). However, a direct comparison between 2019 and 2020 showed a significant reduction in patient presentations in 2020 (Table 2). In relation to the public restriction measures within the framework of the nationwide lockdown intervals, there was a clear decrease in presentations to the dental and oral and maxillofacial surgery emergency services at Mainz University Hospital up to 39\% during the partial lockdown period from 2 November to 15 December 2020 (Table 3). Figure 1 provides an overview of the COVID-19 pandemic year 2020, the development of COVID-19 infection cases as well as the globally adopted measures and the restrictions on public life in Germany. The gender distribution did not differ relative to the number of patients when comparing 2019 and 2020. The same applied to the patients' age distribution and the frequency of visits depending on the weekday. The daytime of the emergency presentation was

Table 3 Trends in dental and craniomaxillofacial emergency services patient numbers in 2019 and 2020, grouping into defined time periods according to federal restriction measures in 2020 and applied these on 2019 for better comparability

\begin{tabular}{|c|c|c|c|}
\hline Time period & Year $2019(\%)$ & Year $2020(\%)$ & $\begin{array}{l}\text { Difference } \\
2019 \text { vs. } 2020 \\
(\%)\end{array}$ \\
\hline $\begin{array}{l}\text { 01.01-21.03 } \\
\text { (Pre-LD) }\end{array}$ & $1024(21.8)$ & $827(22.5)$ & -19 \\
\hline 22.03-19.04 (LD \#1) & $363(7.7)$ & $243(6.6)$ & -33 \\
\hline $20.04-01.11(\mathrm{IM})$ & $2495(53.0)$ & $2092(56.8)$ & -16 \\
\hline $\begin{array}{l}02.11-15.12 \\
\text { (Part.LD) }\end{array}$ & $508(10.8)$ & $311(8.4)$ & -39 \\
\hline $16.12-31.12(\mathrm{LD} \# 2)$ & $317(6.7)$ & $206(5.6)$ & -34 \\
\hline
\end{tabular}

also similar, with a prime-time period between noon and midnight (Table 4). The most common (>95\%) reasons for visits in the dental and CMFS emergency service were pain, accidents with facial trauma, swelling, scheduled presentations/follow-up, dental conservative issues, post-bleedings, assaults and others (Fig. 2).

\section{Disease types, diagnoses and urgency}

The most common diagnosis for presentation in both 2019 (36.4\%) and $2020(32.7 \%)$ were general dental conservative pathologies including caries, crown- or root fractures, acute pulpitis, or apical periodontitis. When comparing 2019 and 2020, there was a significant decrease in frequencies $(p=0.003)$. Orofacial hard and soft tissue traumas including dental trauma, lacerations, central and centrolateral midface and mandibular fractures were second most common in $2019(18 \%)$ and $2020(21.5 \%)$, whereby its total number decreased significantly in $2020(p<0.001)$. Infectiousinflammatory pathologies were the third most common type of diagnosis in 2019 (14.7\%) and 2020 (16\%), with little change in incidence $(p=0.106)$, followed by the diagnosis type "others" $(13.2 \%$ and $11.5 \%)$, scheduled follow-up presentations (9.2\% and $8.3 \%$ ), bleedings (3.3\% and $3.5 \%)$, and facial pain (3\% and 2.3\%; Table 5, Fig. 3). Although less in total, trauma $(+3.5 \%)$ and infectious pathologies $(+1.3 \%)$ have increased proportionately in 2020 when compared to 2019. Among cases with post-bleeding following oral surgery, the proportion taking non-vitamin $\mathrm{K}$ antagonist oral anticoagulants (NOACs) was $20.4 \%$ in $2019(n=32 / 157)$ and $25 \%(n=32 / 129)$ in 2020. Continuous medication with vitamin $\mathrm{K}$ antagonist anticoagulants (OACS) was present in 14\% (22/157) in 2019 and in 18.6\% (24/129) in 2020. Detailed information on the frequency distribution of the diagnoses is given in Table 5. Further, it was shown that the proportion of emergent presentations ${ }^{+++}$increased by $6.3 \%$ in COVID-19 year 2020, and the proportion of urgent ${ }^{++}$ and non-urgent ${ }^{+}$presentations decreased correspondingly by $4.2 \%$ and $2.1 \%$, respectively (Table 6 ).

Pre-LD = time period prior to the first lockdown (LD \#1) in Germany; $\mathrm{IM}=$ intermediate period between first and partial lockdown (Part.LD); LD \#2= second lockdown in Germany.

\section{Lockdown periods}

In correlation with the public restrictions in 2020, except for 2 November through 15 December, there was an increase in cases actually defined as emergent ${ }^{+++}$with a concomitant decrease in urgent ${ }^{++}$and non-urgent ${ }^{+}$presentations during emergency hours (Fig. 4). This, in turn, was also reflected in the number of inpatient admissions during emergency service hours, when the number of 50 (1.1\%) inpatient 


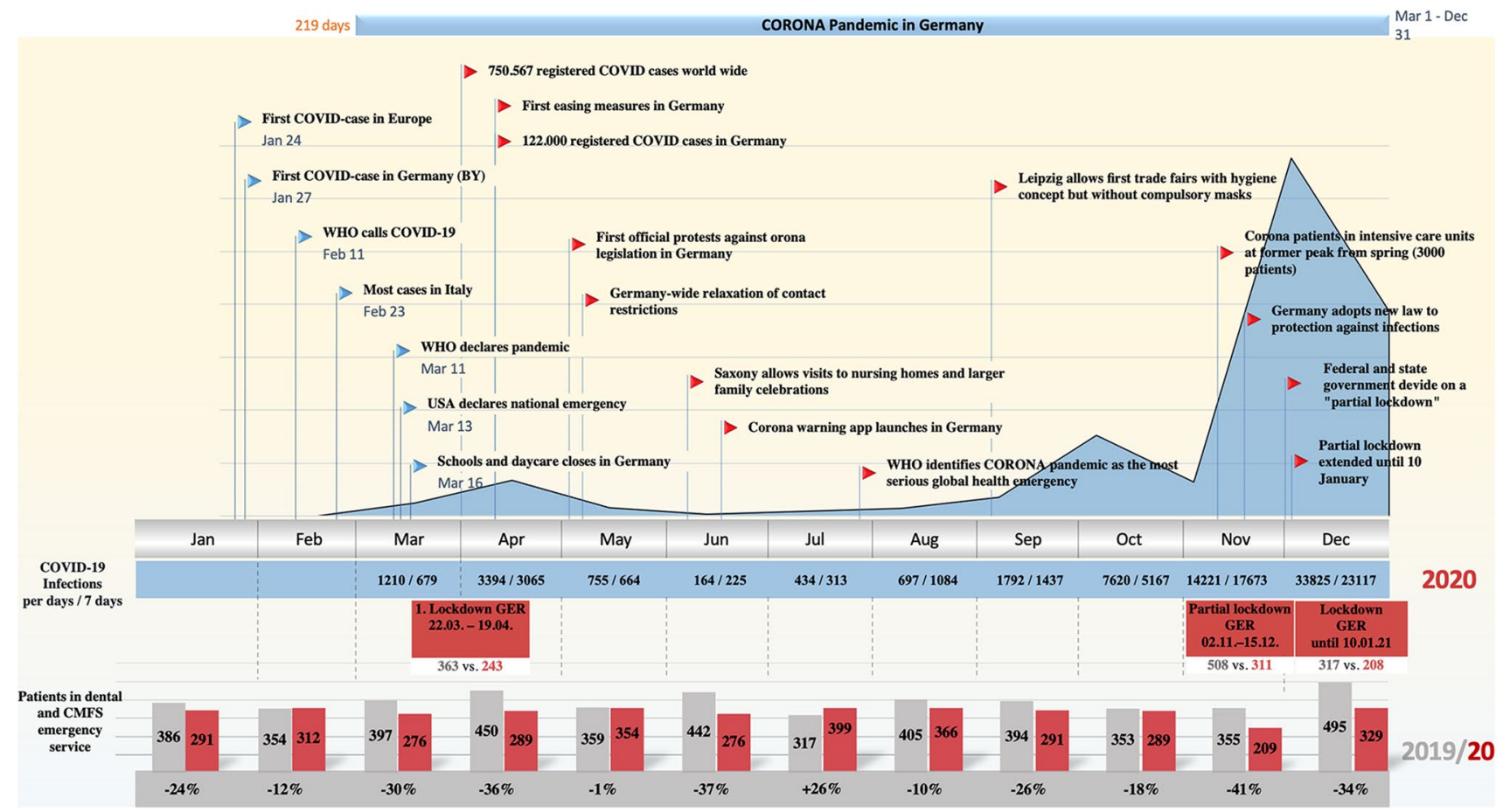

Fig. 1 Timeline shows the COVID-19 year 2020 and the monthly development of the nationwide infection figures, in correlation with the monthly patient numbers of the dental and CMFS emergency ser- vices (red), taking into account the nationwide public health restrictions. The key figures from 2019 are shown in grey for comparison

Other measures ${ }^{(*)}$ include performing temporary refixation of loosened crowns and partial crowns, grinding in dentures that cause pressure points, or removing sharp wire ends of orthodontic appliances.

\section{Discussion}

This is the first study to examine the impact of the COVID19 pandemic on the emergency dental and maxillofacial services of a German university hospital in 2020 compared to the previous year 2019 in relation to the German federal restriction measures (lockdown periods). Limitations of the present study are the limited transferability of the data to other countries, which is not least due to the country-specific regulations on the health system under pandemic conditions, as well as the inherent limitations of retrospective studies. This includes the evaluation of partially incomplete data sets, as the definition of specific parameters of interest is missing, unlike a prospective study design, and results may be influenced by parameters that were not recorded at all $[9,10]$. More years could have been used as a reference period, as the comparison year 2019 could be an exception. However, this was not done, taking into account an earlier study on the emergency dental service of our university hospital in the 
Table 4 Characteristics of dental and oral and maxillofacial surgery emergency service patients compared in 2019 and 2020

\begin{tabular}{|c|c|c|c|c|c|c|c|}
\hline \multirow[t]{2}{*}{ Variables } & \multirow{2}{*}{$\begin{array}{l}\text { Year } 2019(\%) \\
\text { Count }\end{array}$} & \multicolumn{6}{|c|}{ Year $2020(\%)$} \\
\hline & & Count & Pre-LD & $\mathrm{LD} \# 1$ & $\mathrm{IM}$ & Part-LD & LD \#2 \\
\hline Total & 4707 & 3679 & $827(22.5)$ & $243(6.6)$ & $2092(56.8)$ & $311(8.4)$ & $206(5.6)$ \\
\hline \multicolumn{8}{|l|}{ Gender } \\
\hline Female & $2121(45.1)$ & $1675(45.5)$ & $350(42.3)$ & $114(46.9)$ & $971(46.4)$ & $149(47.9)$ & $91(44.2)$ \\
\hline Male & $2586(54.9)$ & $2004(54.5)$ & $477(57.5)$ & $129(53.1)$ & $1121(53.6)$ & $162(52.1)$ & $115(55.8)$ \\
\hline \multicolumn{8}{|l|}{ Age group (years) } \\
\hline $0-3$ & $228(4.8)$ & $189(5.1)$ & $34(4.1)$ & $18(7.4)$ & $114(5.4)$ & $13(4.2)$ & $10(4.9)$ \\
\hline $4-14$ & $481(10.2)$ & $392(10.7)$ & $81(9.8)$ & $28(11.5)$ & $232(11.1)$ & $34(10.9)$ & $17(8.3)$ \\
\hline $15-30$ & 1299 (27.6) & $948(25.8)$ & $215(26)$ & $56(23)$ & $555(26.5)$ & $71(22.8)$ & $51(24.8)$ \\
\hline $31-65$ & $2171(46.1)$ & $1698(46.2)$ & $399(48.2)$ & $114(46.9)$ & $920(44.0)$ & $165(53.1)$ & $100(48.5)$ \\
\hline $66-80$ & $383(8.1)$ & $311(8.5)$ & $70(8.5)$ & $19(7.8)$ & $185(8.8)$ & $16(5.1)$ & $21(10.2)$ \\
\hline$>80$ & $145(3.1)$ & $141(3.8)$ & $28(3.4)$ & $8(3.3)$ & $86(4.1)$ & $12(3.9)$ & $7(3.4)$ \\
\hline \multicolumn{8}{|l|}{ Weekday } \\
\hline Monday & $376(8)$ & $293(8)$ & $67(8.1)$ & $33(13.6)$ & $160(7.6)$ & $19(6.1)$ & $14(6.7)$ \\
\hline Tuesday & $361(7.7)$ & $223(6.1)$ & $47(5.7)$ & $11(4.5)$ & $136(6.5)$ & $21(6.8)$ & $8(3.8)$ \\
\hline Wednesday & 368 (7.8) & $269(7.3)$ & $78(9.4)$ & $10(4.1)$ & $152(7.3)$ & $20(6.4)$ & $9(4.3)$ \\
\hline Thursday & $354(7.5)$ & $324(8.8)$ & $64(7.7)$ & $22(9.1)$ & $164(7.8)$ & $22(7.1)$ & $52(25)$ \\
\hline Friday & $516(11)$ & $482(13.1)$ & $77(9.3)$ & $37(15.2)$ & $291(13.9)$ & $46(14.8)$ & 31 (14.9) \\
\hline Saturday & $1411(30)$ & $1134(30.8)$ & 295 (35.7) & $63(25.9)$ & $623(29.8)$ & $102(32.8)$ & $51(24.5)$ \\
\hline Sunday & $1321(28.1)$ & $956(26)$ & $199(24.1)$ & 67 (27.6) & $566(27.1)$ & $81(26)$ & $43(20.7)$ \\
\hline \multicolumn{8}{|l|}{ Daytime } \\
\hline Midnight-6:00 & $271(5.8)$ & $222(6.0)$ & $51(6.2)$ & $8(3.3)$ & $148(7.1)$ & $9(2.9)$ & $6(2.9)$ \\
\hline 6:01-noon & 1065 (22.6) & 797 (21.7) & $185(22.4)$ & $58(23.9)$ & $428(20.5)$ & $66(21.2)$ & $60(29.1)$ \\
\hline $12: 01-18: 00$ & $1623(34.5)$ & $1329(36.1)$ & $299(36.2)$ & 97 (39.9) & $730(34.9)$ & $120(38.6)$ & $83(40.3)$ \\
\hline $6: 01-23: 59$ & $1748(37.1)$ & $1331(36.2)$ & $292(35.3)$ & $80(32.9)$ & 786 (37.6) & $116(37.3)$ & $57(27.7)$ \\
\hline
\end{tabular}



Fig. 2 Bar chart shows the distribution of patient-side reasons for presentation in dental and maxillofacial emergency services in comparison of the years 2019 (grey) and 2020 (red) years 2010-2013 [2]. The epidemiological data included patient characteristics, reasons for presentation and times, as well as diagnoses made and treatments carried out. This revealed that the number of emergency service visits in 2020 decreased significantly by $22 \%$ compared to 2019 . Broken down by month, there were proportional peaks of up to $-41 \%$ in November 2020 , but also a $26 \%$ increase in visits in July 2020 . The evaluation by defined time periods, which corresponded to the periods of the federal public life restriction measures, compared to the same periods in 2019, showed a decrease in emergency service visits of $33 \%$ during the first lockdown (22 March 2020 to 19 April 2020 ), by $39 \%$ during the partial lockdown (2 November 2020 to 15 December 2020) and 34\% during the second lockdown from 16 December 2020 to 31 December 2020. This, as well as the phenomenon of a proportionally significant increase in individual types of diagnosis (e.g. trauma and infectious pathologies) with a simultaneous decrease in the total number of emergency presentations, was consistent with the study results of the Italian study group around Cagetti et al. [11]. In contrast, a Swiss study showed an increase in daily case numbers during the lockdown periods, but only the pre-COVID period 2020 served 
Table 5 Diagnoses made by the physician/dentist for emergency presentation

\begin{tabular}{|c|c|c|c|c|}
\hline \multirow[b]{2}{*}{ Diagnosis type } & \multirow[b]{2}{*}{ Diagnosis } & \multirow{2}{*}{$\begin{array}{l}\text { Year } 2019 \\
\text { Count }(\%)\end{array}$} & \multirow{2}{*}{\begin{tabular}{|l|} 
Year 2020 \\
Count $(\%)$
\end{tabular}} & \multirow[t]{2}{*}{ P-Value $\left(X^{2}\right.$-test) } \\
\hline & & & & \\
\hline \multirow{7}{*}{$\begin{array}{l}\text { Conservative } \\
\text { dental issues }\end{array}$} & Acute pulpitis ${ }^{++}$ & $501(10.6)$ & $230(6.3)$ & \\
\hline & Periodontitis $^{+}$ & $118(2.5)$ & $33(0.9)$ & \\
\hline & Tooth structure defects (tooth or crown & & & \\
\hline & fracture $)^{++}$ & $1096(23.3)$ & 939 (25.5) & \\
\hline & Loosened fillings $^{++}$ & (3) & ) & \\
\hline & Caries $^{++}$ & & & \\
\hline & & $1715(36.4)$ & $1202(32.7)$ & 0.003 \\
\hline \multirow[t]{6}{*}{ Trauma } & Anterior dental trauma ${ }^{+++}$ & $325(6.9)$ & $309(8.4)$ & 0.01 \\
\hline & Intra- and extraoral soft tissue trauma ${ }^{+++}$ & $445(9.5)$ & $378(10.3)$ & 0.066 \\
\hline & Midface fracture ${ }^{+++}$ & $25(0.5)$ & $52(1.4)$ & $<0.001$ \\
\hline & Mandible fracture ${ }^{+++}$ & $22(0.5)$ & $34(0.9)$ & 0.011 \\
\hline & Alveolar process fracture ${ }^{+++}$ & $32(0.7)$ & $18(0.5)$ & 0.261 \\
\hline & & $849(18)$ & $791(21.5)$ & $<0.001$ \\
\hline \multirow[t]{7}{*}{ Infections } & Submucosal abscess $^{+++}$ & $269(5.7)$ & $255(6.9)$ & 0.002 \\
\hline & Periodontal abscess $^{+++}$ & $189(4)$ & $100(2.7)$ & 0.001 \\
\hline & Lodge abscess ${ }^{+++}$ & $96(2)$ & $145(3.9)$ & $<0.001$ \\
\hline & Pericoronitis $^{++}$ & $118(2.5)$ & $67(1.8)$ & 0.034 \\
\hline & Maxillary sinus empyema ${ }^{+++}$ & 0 & $1(0.03)$ & 0.258 \\
\hline & Cervicofacial soft tissue inflammation ${ }^{*+++}$ & $20(0.4)$ & $20(0.5)$ & 0.434 \\
\hline & & $692(14.7)$ & $588(16)$ & 0.106 \\
\hline \multirow[t]{16}{*}{ Other disease } & Oral mucosal disease (gingivitis, oral lichen & $126(2.7)$ & $92(2.5)$ & 0.666 \\
\hline & planus, burning mouth) ${ }^{++}$ & & & \\
\hline & Orthodontic emergency $^{++}$ & $79(1.7)$ & $47(1.3)$ & 0.134 \\
\hline & Bone cyst $^{+}$ & $9(0.2)$ & $7(0.2)$ & 0.992 \\
\hline & Oroantral communication $^{+}$ & $4(0.1)$ & $5(0.1)$ & 0.48 \\
\hline & Sialadenitis $^{++}$ & $29(0.6)$ & $11(0.3)$ & 0.036 \\
\hline & TMJ arthropathy $^{+}$ & $46(1)$ & $42(1.1)$ & 0.464 \\
\hline & TMJ dislocation $^{+++}$ & $12(0.3)$ & $25(0.7)$ & 0.004 \\
\hline & $\begin{array}{l}\text { Postoperative complication (wound- dehiscence } \\
\text { or infection, dry socket) }\end{array}$ & $230(4.9)$ & $134(3.6)$ & 0.006 \\
\hline & Animal bite ${ }^{+++}$ & $3(0.1)$ & $9(0.2)$ & 0.03 \\
\hline & Sinusitis $^{+}$ & $8(0.2)$ & $8(0.2)$ & 0.621 \\
\hline & Cervicofacial emphysema $^{+++}$ & $3(0.1)$ & $2(0.1)$ & 0.861 \\
\hline & Lymphadenopathy $^{+}$ & $4(0.1)$ & $7(0.2)$ & 0.186 \\
\hline & Prosthetic issues $^{+}$ & $66(1.4)$ & $34(0.9)$ & 0.045 \\
\hline & Cancer $^{+}$ & $3(0.1)$ & $1(0.03)$ & 0.447 \\
\hline & & $622(13.2)$ & $424(11.5)$ & 0.020 \\
\hline $\begin{array}{l}\text { Scheduled } \\
\text { presentations }\end{array}$ & Follow-up & $435(9.2)$ & $305(8.3)$ & 0.128 \\
\hline Bleeding & Post bleeding ${ }^{+++}$ & $157(3.3)$ & $129(3.5)$ & 0.669 \\
\hline \multirow[t]{3}{*}{ Pain } & Facial pain $^{++}$ & $140(3)$ & $82(2.2)$ & 0.035 \\
\hline & Trigeminal neuralgia $^{++}$ & $3(0.1)$ & $3(0.1)$ & 0.762 \\
\hline & & $143(3.01)$ & $85(2.3)$ & 0.042 \\
\hline
\end{tabular}

Cervicofacial infections $(*)$ include cutaneous abscesses, boils, infected atheromas, phlegmon and erysipelas. Assignment to one of the urgency groups is indicated by the superscript + signs $(+++=$ emergent; $++=$ urgent; $+=$ non-urgent $)$ 
Fig. 3 Bar chart showing the distribution of diagnosis types in dental and maxillofacial emergency services comparing 2019 (grey) and 2020 (red)



as a reference [8]. Regarding the number of odontogenic infections, an American study by Johnson et al. showed a numerical decrease over the limited period from March to June, but a proportional increase compared to the years 2017-2019 [12]. Overall, there is currently little epidemiological data on the use of dental emergency service in connection with the COVID-19 pandemic. Most of the studies published so far are from 2020, describe the situation outside Europe (East Asia or South America) [13, 14] and only highlight parts of the year [15], so they do not provide information on the situation in Europe, nor the characteristics of emergency service visits over the course of the COVID-19 infection waves and the associated constraints on public life [14, 16-18]. The decrease in the total number of patients due to the COVID-19 pandemic in 2020 shown in this study is consistent with the findings of other studies $[11,19]$. However, the varying

Table 6 Number and proportion (\%) of cases grouped by urgency and presented comparing 2019 and 2020

\begin{tabular}{|c|c|c|c|}
\hline Urgency & Year $2019(\%)$ & Year $2020(\%)$ & $P$ value $\left(\chi^{2}\right.$ test $)$ \\
\hline Emergent $^{+++}$ & $1633(34.7)$ & $1508(41)$ & $<0.001$ \\
\hline $\begin{array}{l}\text { Inpatient admis- } \\
\text { sion }\end{array}$ & $45(2.8)$ & 129 (8.6) & \\
\hline Urgent $^{++}$ & $2174(46.2)$ & $1545(42)$ & $<0.001$ \\
\hline $\begin{array}{l}\text { Inpatient admis- } \\
\text { sion }\end{array}$ & $5(0.2)$ & $8(0.5)$ & \\
\hline Non-urgent $^{+}$ & $900(19.1)$ & $625(17)$ & 0.012 \\
\hline $\begin{array}{l}\text { Inpatient admis- } \\
\text { sion }\end{array}$ & - & $7(1.1)$ & \\
\hline Total & $\begin{array}{l}4707 \\
50(1.1)\end{array}$ & $\begin{array}{l}3679 \\
144(3.9)\end{array}$ & $<0.001$ \\
\hline
\end{tabular}

availability of the emergency units should be taken into account, which has an influence on the number of patients recorded $[11,17,20]$. The isolated increase of $26 \%$ in emergency service visits in July 2020 compared to the previous year observed in this study also seems to follow a certain systematic approach, taking into account recent study results from Italy. In this regard, the group of authors around Cagetti et al. showed that there was an increase in emergency service requests in the period after general relaxations of COVID-related restrictions on public life [11]. An explanation for this is the general uncertainty of the population and (dental) healthcare professionals, which is due not least to the fear of infections, but also to non-existent or controversial recommendations by professional societies and governments, and which has led to a delayed use of a medical examination with aggravation of the diagnostic severity and urgency. In detail, these were inconsistent regulations on the maintenance of outpatient care in the field of dentistry and general medicine, as well as the definition of urgently necessary and avoidable treatments. An example of this is the risk of aerosol formation in the context of dental treatments, which was discussed at the beginning but is difficult to avoid in theory and practice. Contrary to the fear of self-infection, a recent study from India on paediatric dental treatments during the COVID-19 pandemic could not prove any infection of dental staff in the course of aerosol-generating therapy measures [21]. At the beginning of the pandemic, orthodontic treatments should therefore be continued in Germany due to almost no aerosol formation but indicated continuation of treatments already started, whereas periodontal therapies or prophylactic treatments should be suspended. This theory is supported by the results of studies that have 


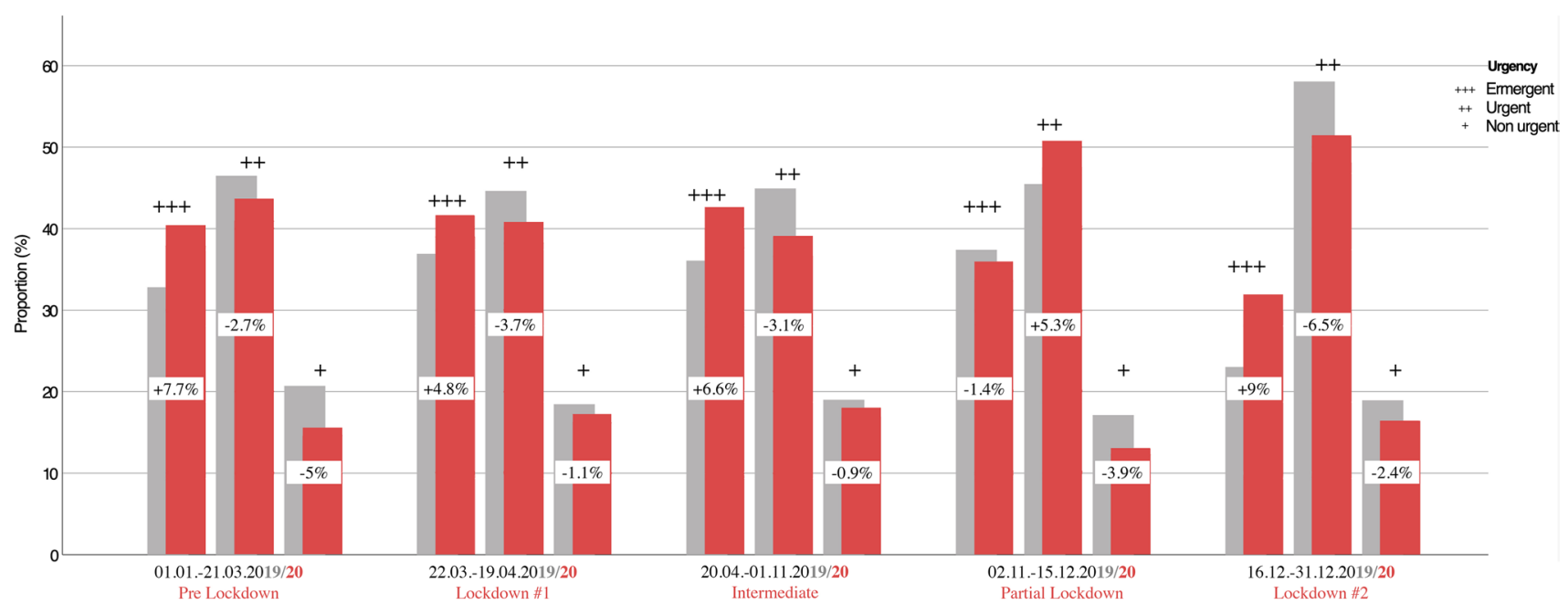

Fig. 4 Bar chart shows the distribution of cases classified as emergency $(+++)$, urgent $(+++)$ and non-urgent $(+)$ in correlation to the federal lockdown periods comparing 2019 (grey) and 2020 (red)

shown a direct link between a decrease in dental treatments and patient fear of SARS-CoV-2 infection [22-24]. One possible solution is seen in open doctor-patient communication, explaining to the patient the measures taken by the treating institution to minimise the incidence of infection, and highlighting the positive and negative consequences of treatment [25]. Despite fewer overall visits during emergency hours in 2020 , our study revealed that there was an increase in the proportion of cases defined

Table 7 Therapeutic measures and their frequency compared between 2019 and 2020

\begin{tabular}{|c|c|c|c|}
\hline Therapy & $\begin{array}{l}\text { Year } 2019 \\
\text { Count }(\%)\end{array}$ & $\begin{array}{l}\text { Year } 2020 \\
\text { Count }(\%)\end{array}$ & $P$ value $\left(\chi^{2}\right.$ test $)$ \\
\hline Tooth/jaw splinting & $84(1.8)$ & $84(2.3)$ & 0.11 \\
\hline $\begin{array}{l}\text { Dental conservation } \\
\text { measures }\end{array}$ & $615(13.1)$ & $454(12.3)$ & 0.32 \\
\hline Endodontic measures & $628(13.3)$ & $452(12.3)$ & 0.15 \\
\hline Surgical measures & $488(10.4)$ & $452(12.3)$ & 0.006 \\
\hline Abscess incision & $471(10)$ & $379(10.3)$ & 0.66 \\
\hline $\begin{array}{l}\text { Local haemostatic } \\
\text { measures }\end{array}$ & $140(3)$ & $82(2.2)$ & 0.97 \\
\hline $\begin{array}{l}\text { Conservative (sympto- } \\
\text { matic non-invasive) } \\
\text { measures }\end{array}$ & $1744(37.1)$ & $1367(37.2)$ & 0.92 \\
\hline $\begin{array}{l}\text { Consultative co-assess- } \\
\text { ment }\end{array}$ & $42(0.9)$ & $62(1.7)$ & 0.001 \\
\hline Follow-up care & $451(9.6)$ & $305(8.3)$ & 0.02 \\
\hline Other measures* & $138(2.9)$ & $122(3.3)$ & 0.31 \\
\hline TMJ reposition & $12(0.3)$ & $24(0.7)$ & 0.006 \\
\hline $\begin{array}{l}\text { Prescription of antibiot- } \\
\text { ics }\end{array}$ & $447(9.5)$ & $562(15.3)$ & 0.03 \\
\hline
\end{tabular}

as emergent ${ }^{+++}(+6 \%)$, with a simultaneous decrease in urgent $^{++}(-4.2 \%)$ and non-urgent ${ }^{+}$presentations $(-2.1 \%)$. This was in line with the increasing proportion of patients who were further admitted for stationary care following emergency presentation as it tripled in 2020 compared with 2019 , with almost $90 \%$ of cases classified as "emergent" $(p<0.001)$.

\section{Conclusions}

The year 2020 has not only shown the imperative need to secure a dental as well as maxillofacial surgery emergency service system, but equally the importance of stable basic dental and maxillofacial surgical care in times of pandemic. However, this requires the provision of uniform, cross-national recommendations for action and government regulations by relevant professional societies and politics.

Authors' contributions All authors read and approved the final manuscript and take responsibility for the integrity of the work as a whole, from inception to finished article. D.T. substantially contributed to the conception and the design of the study, acquisition, analysis and interpretation of data as well as drafted the manuscript. P.M. substantially contributed to acquisition, analysis and interpretation of data. R.P. substantially contributed to acquisition, analysis and interpretation of data. M.G. substantially contributed to acquisition, analysis and interpretation of data. B.S. substantially contributed to acquisition, analysis and interpretation of data. B.A. contributed to data interpretation and substantively revised the manuscript. P.K. substantially contributed to data interpretation to the conception and the design of the study and substantively revised the manuscript. 
Funding Open Access funding enabled and organized by Projekt DEAL.

Availability of data and materials The datasets used and/or analysed during the current study are available from the corresponding author on request.

\section{Declarations}

Ethics approval and consent to participate The study was approved by the local ethic committee of Rhineland-Palate (registration number 2020-14952) and was conducted in accordance with the protocol and in compliance with the moral, ethical and scientific principles governing clinical research as set out in the Declaration of Helsinki of 1975 as revised in 1983 .

Authors' information The results of the present study are part of the doctoral thesis of the co-author and student of the University of Mainz, M.P., and as such will be made publicly available as part of the doctorate.

Consent for publication Not applicable.

Competing interests The authors declare that they have no competing interests.

Open Access This article is licensed under a Creative Commons Attribution 4.0 International License, which permits use, sharing, adaptation, distribution and reproduction in any medium or format, as long as you give appropriate credit to the original author(s) and the source, provide a link to the Creative Commons licence, and indicate if changes were made. The images or other third party material in this article are included in the article's Creative Commons licence, unless indicated otherwise in a credit line to the material. If material is not included in the article's Creative Commons licence and your intended use is not permitted by statutory regulation or exceeds the permitted use, you will need to obtain permission directly from the copyright holder. To view a copy of this licence, visit http://creativecommons.org/licenses/by/4.0/.

\section{References}

1. Hammel JM, Fischel J (2019) Dental emergencies. Emerg Med Clin North Am 37(1):81-93. https://doi.org/10.1016/j.emc.2018.09.008

2. Weusmann J, Schmitt H, Braun B, Sagheb K, Willershausen B, Mahmoodi B (2020) Gender-specific differences of dental emergency patients and the use of antibiotics: a 4-year retrospective study. Oral Health Prev Dent 18(1):263-269. https://doi.org/10. 3290/j.ohpd.a44037

3. Kim C, Choi E, Park KM, Kwak EJ, Huh J, Park W (2019) Characteristics of patients who visit the dental emergency room in a dental college hospital. J Dent Anesth Pain Med 19(1):21-27. https://doi.org/10.17245/jdapm.2019.19.1.21

4. What Constitutes a Dental Emergency? (2020) https://success.ada. org/ /media/CPS/Files/Open\%20Files/ADA_COVID19_Dental_ Emergency_DDS.pdf?_ga=2.78740951.215793349.1585680652310524266.1585339538. Accessed 31.03.2020

5. Ren YF, Rasubala L, Malmstrom H, Eliav E (2020) Dental care and oral health under the clouds of COVID-19. JDR Clin Trans Res 5(3):202-210. https://doi.org/10.1177/2380084420924385
6. National Dental Advisory Committee N (2007) Scottish Dental Clinical Effectiveness Programme (SDCEP). Emergency Dental Care. National Dental Advisory Committee (NDAC)

7. Gurzawska-Comis K, Becker K, Brunello G, Gurzawska A, Schwarz F (2020) Recommendations for dental care during COVID-19 pandemic. J Clin Med 9(6). https://doi.org/10.3390/ jcm9061833

8. Eggmann F, Haschemi AA, Doukoudis D, Filippi A, Verna C, Walter C, Weiger R, Zitzmann NU, Bornstein MM (2021) Impact of the COVID-19 pandemic on urgent dental care delivery in a Swiss university center for dental medicine. Clin Oral Investig. https://doi.org/10.1007/s00784-021-03872-1

9. Altman DG, Bland JM (2007) Missing data. BMJ 334(7590):424. https://doi.org/10.1136/bmj.38977.682025.2C

10. Talari K, Goyal M (2020) Retrospective studies - utility and caveats. J R Coll Phys Edinb 50(4):398-402. https://doi.org/10.4997/ JRCPE.2020.409

11. Cagetti MG, Balian A, Camoni N, Campus G (2021) Influence of the COVID-19 pandemic on dental emergency admissions in an urgent dental care service in North Italy. Int J Environ Res Public Health 18(4). https://doi.org/10.3390/ijerph18041812

12. Johnson RE 3rd, Foy TE, Ellingsen TA, Nelson JL, Dillon JK (2021) Odontogenic infections: disease burden during COVID19 at a single institution. J Oral Maxillofac Surg 79(4):830-835. https://doi.org/10.1016/j.joms.2020.10.015

13. Wang C, Miao L, Wang Z, Xiong Y, Jiao Y, Liu H (2020) Emergency management in dental clinic during the Coronavirus Disease 2019 (COVID-19) epidemic in Beijing. Int Dent J. https:// doi.org/10.1111/idj.12609

14. Peloso RM, Pini NIP, Sundfeld Neto D, Mori AA, Oliveira RCG, Valarelli FP, Freitas KMS (2020) How does the quarantine resulting from COVID-19 impact dental appointments and patient anxiety levels? Braz Oral Res 34:e84. https://doi.org/10.1590/18073107bor-2020.vol34.0084

15. Langella J, Magnuson B, Finkelman MD, Amato R (2020) Clinical response to COVID-19 and utilization of an emergency dental clinic in an academic institution. J Endod. https://doi.org/10. 1016/j.joen.2020.11.025

16. Bai J, Xu T, Ji AP, Sun W, Huang MW (2020) Impact of COVID19 on oral emergency services. Int Dent J. https://doi.org/10.1111/ idj. 12603

17. Wu JH, Lee MK, Lee CY, Chen NH, Lin YC, Chen KK, Lee KT, Du JK (2021) The impact of the COVID-19 epidemic on the utilization of dental services and attitudes of dental residents at the emergency department of a medical center in Taiwan. J Dent Sci. https://doi.org/10.1016/j.jds.2020.12.012

18. Blackhall KK, Downie IP, Ramchandani P, Kusanale A, Walsh S, Srinivasan B, Shields H, Brennan PA, Singh RP (2020) Provision of emergency maxillofacial service during the COVID-19 pandemic: a collaborative five centre UK study. Br J Oral Maxillofac Surg 58(6):698-703. https://doi.org/10.1016/j.bjoms.2020.05.020

19. Bai J, Xu T, Ji AP, Sun W, Huang MW (2021) Impact of COVID19 on oral emergency services. Int Dent J 71(1):27-31. https:// doi.org/10.1111/idj.12603

20. Lee YL, Hu HY, Yen YF, Chu D, Yang NP, Chou SY, Lin SY, Chu CM, Huang SJ (2021) Impact of the COVID-19 pandemic on the utilization of medical and dental services in Taiwan: a cohort study. J Dent Sci. https://doi.org/10.1016/j.jds.2021.02.001

21. Samuel SR, Mathew MG, Suresh SG, Varma SR, Elsubeihi ES, Arshad F, Elkareimi Y, Elsahn NA, Khalil E (2021) Pediatric dental emergency management and parental treatment preferences during COVID-19 pandemic as compared to 2019. Saudi J Biol Sci 28(4):2591-2597. https://doi.org/10.1016/j.sjbs.2021.02.002 
22. Shamsoddin E, DeTora LM, Tovani-Palone MR, Bierer BE (2021) Dental care in times of the COVID-19 pandemic: a review. Med Sci (Basel) 9(1). https://doi.org/10.3390/medsci9010013

23. Huang Y, Zhao N (2020) Generalized anxiety disorder, depressive symptoms and sleep quality during COVID-19 outbreak in China: a web-based cross-sectional survey. Psychiatry Res 288:112954. https://doi.org/10.1016/j.psychres.2020.112954

24. Gonzalez-Olmo MJ, Ortega-Martinez AR, Delgado-Ramos B, Romero-Maroto M, Carrillo-Diaz M (2020) Perceived vulnerability to Coronavirus infection: impact on dental practice. Braz
Oral Res 34:e044. https://doi.org/10.1590/1807-3107bor-2020. vol34.0044

25. Wang TT, Wang S (2021) Applying behavioral economics to address COVID-19 fear among oral and maxillofacial surgery patients. J Oral Maxillofac Surg 79(4):741-742. https://doi.org/ 10.1016/j.joms.2020.12.020

Publisher's note Springer Nature remains neutral with regard to jurisdictional claims in published maps and institutional affiliations. 